\title{
Research on Talent Cultivation Mechanism of Costume Art Design in Fashion Industry
}

\author{
Yuan Li \\ Xi'an Peihua University, Xi’an, Shaanxi, 710125
}

Keywords: clothing; art design; talent; fashion

\begin{abstract}
The so-called "art design" is based on different angles such as technical, economic, and cultural perspectives, with high-efficiency utilization as an activity goal, and material materials and technological techniques to adapt to certain artistic means, and design planning according to aesthetic laws, combining functions, external forms, and cultural heritage in the creation of use-items, including functionality as the main design goal of the actual product and aesthetic-oriented viewing products, etc. The four major areas of clothing, food, housing and transportation are very extensive, and the most representative one is the clothing industry. Both the influence of the industry and the development trend of the industry have largely determined the direction of the development of the world trend. However, after all, the clothing industry is still a traditional industry, and there are drawbacks that hinder its development. It is necessary to strengthen the beginning and end of the "smile curve" to further realize high value-added products. Judging from the current status quo of the industry, the driving force behind the development of the apparel industry and the driving force for product innovation in the cultivation of design talents in the apparel industry, and it is necessary to establish an excellent art design talent training mechanism.
\end{abstract}

\section{Introduction}

In the process of development, the fashion industry not only integrates the concept of advanced manufacturing with large-scale production, but also inherits the art of traditional handicrafts. In the process of people's consumption, people often reflect the aesthetic needs of the people and also inherit the traditional culture. The essence. Fashion industry has its rich connotation, often through the factors such as artistry, creativity and consumption, to integrate and sublimate various resources of traditional industries to form a relatively unique mode of operation of goods. Its products are mainly for consumers to provide the most popular aesthetic standards and consumer services.

\section{The Status and Direction of Clothing Industry in Fashion Industry}

The training direction of China's fashion design talents includes a complete education system composed of arts, engineering, and technology, and now there are three models for the training of talents in the clothing industry: first, the costume design and craft direction in vocational and technical education, the direction of The focus is on the teaching of garment technology. The aim is to enable students to master a certain degree of garment technology and to cultivate senior technicians and practical technical talents. The demand for such talents in China's garment industry is very large, but also occupy Very important position. Secondly, the major of fashion design and engineering is to cultivate the direction of the garment engineering. The curriculum is also more focused on the direction of materials and production management. The cultivated talents are mostly garment engineers and are the backbone of the garment industry. Thirdly, in the direction of fashion design, most art colleges fall into this category. The main production basis is the production of garment industry. Comprehensive talents combining theory and practice are cultivated, and how to cultivate the design talents of the garment industry and establish The outstanding talents training mechanism for art and design is the focus of this study.

With the rapid development of China's economy, the apparel industry has continued to flourish. 
The development and innovation of the apparel industry depends on the cultivation of talented designers of arts and fashion. Since the development of higher arts education, the disciplines of the art education system have become more and more perfect. At the same time, the subject system has also become more and more scientific, forming an art education system with a certain scale. However, there is still a lot of space for the training of professional clothing design talents.

The garment industry is an important part of improving people's lives and improving their quality of life. It is the country's basic consumer industry. The continuous improvement of people's material and cultural levels and the development of the times have led to a great breakthrough in human cultural creativity. The apparel industry is The fashion industry bears the responsibility of stimulating the national economy, improving the quality of life of the people, and promoting human civilization.

While China's various reforms are constantly advancing, the apparel industry, as an important part of national life, faces many problems that need to be tackled and overcome difficulties, facing the complex situation at home and abroad, the adjustment of industrial structure and the ability to reform and innovate. Ascension is the direction of reform, and it is also the way to improve China's international competitiveness in the fashion industry. In the "Internet+" era, fashion elements and innovative elements of the apparel industry bring us new ideas through the Internet. This determines that the Internet will become the main battlefield for the upgrading and transformation of the apparel industry in the future.

With the continuous development of the clothing brand, various innovative forces have also been continuously strengthened, and entrepreneurs are paying more and more attention to the brand's core technology and creative nuclear power. Relying on the continuous transformation success, many brand companies also let us see the future development potential of traditional industries. In the development of networked society, the same is true of the apparel industry. Computers make the production chain of the garment industry more efficient and scientific, but also rich. In our lives, the network has made the design and the market become integrated, which has led to the development of a multi-point linkage of the traditional apparel industry.

The allocation of resources in various regions of our country is very clear. The integration and interaction under the mechanism of division of labor and cooperation are also constant in the international community. Cross-border and cross-regional integration of resources across industries has intensified, and developing countries and developed countries have emerged. With frequent interactions, various cooperation models have been continuously developed. As the main force of the fashion industry, the apparel industry will become better and better as it strengthens the culture, creativity and social service of the industry. The apparel industry has improved people's quality of life while bringing fashion concepts to consumers. As a result, consumer purchasing behavior has begun to change dramatically. The promotion of consumers' concept of fashion has also accelerated the speed of updating domestic products, and various ecological and branded products have begun to dominate. Foreign brands such as Uniqlo will quickly occupy the domestic consumer market because of their eco-branding design.

The main reason for the slow development of the apparel industry in China is the lack of innovation and the lack of original design. This leads to a lack of supply to the apparel market. An important way to solve this problem is to carry out reforms and innovations under the structural adjustment of the supply side. Promoting the development of original concepts in the design of garments and mobilizing the linkage mechanism of the industrial chain, enabling the market to develop healthily, and at the same time promoting the links between arts and technology and fashion elements and the human living environment, so that people's designs can meet the needs of consumers.

After the fashion industry has added a variety of factors, our lives have become omnipresent and fashionable everywhere. With culture as the basis of fashion development, promoting the progress of cross-border thinking and the broadening of the international perspective, the fashion industry and the design industry have begun to merge with each other, and there is no clear boundary. In the development of the clothing brand, a piece of product expression Out of the innovative ideas make 
a piece of products more international and national.

\section{Integrate Fashion Industry into the Training Mechanism for Talents in Fashion Art Design}

Established a network interaction platform on which the content of courseware and excellent student works can be displayed on the platform for interaction. Using the mobile phone as a classroom tool, push and share information with the APP or the public number that can share fashion information. It avoids the narrowness of traditional control measures.

Talent as a clothing industry should have a keen sense of fashion no matter what kind of position, have a super comprehensive quality, have the ability to accurately obtain fashion trends and fashion information channels, and apply it in learning and work. . Including fashion teaching into the network information resources and other media is an effective way to enrich yourself. We must be able to guide and help students and cultivate outstanding talents.

In the process of cultivating talents for fashion arts and design, we should establish contact with famous fashion information websites in China, and regularly present excellent student and teacher works on this webpage, so as to expand the professional influence in the entire apparel industry. In the process of setting up teaching content, we must attach importance to the physical characteristics of apparel products and the basic needs of the big market, link the results of the displayed work with the brand, and link through the sales links of the buyer's shop and the integrated market, and use the plant. Inbound teaching can open up conversion channels, help students learn excellent design results, motivate their students' passion for learning, and link the results of design and development with the needs of the company through a complete biological chain, and cultivate enterprise-oriented talents.

Through the famous fashion information website in China, it has established a connection with companies. The garment industry is very practical. Many high art academies and universities are often not skilled in the training of talents and skills, and it is necessary to clarify the cultivation of higher art academies. Talents are all needed by enterprises and society. Therefore, we must also pay attention to the needs of enterprises to a certain extent and innovate the mode of education. In order to meet the needs of the social apparel industry, China's higher art academies' clothing education constantly adjusts the orientation of talent cultivation and forms a new educational structure. New types of clothing education have prompted schools and companies to form two fixed learning places, and they are learning theories. At the same time strengthen the practice of activities. School-enterprise cooperation allows students to understand the situation of the garment industry during school and lay a good foundation for entering the community in the future.

For the program of the professional courses in the apparel industry, students must have a certain degree of sensitivities to the elements of fashion and the ability to collect information, and control the entire process of information resources as a whole. The development of apparel products is connected by many processes. Searching and organizing internationally popular elements and guiding strategic planning through existing materials are very important steps in the process of brand development and are the soul of product development.

Talents for the apparel industry should use international perspectives to guide, accelerate international cooperation, and formulate learning methods and education models that are suitable for students. Only in this way can the apparel industry be able to adapt to the talent needs of the society and meet the actual needs of the company.

The teaching of the garment industry must be based on various educational resources. At the same time, the optimization of disciplines should be carried out. The training methods for interactive talents should be established, and the connotations of various disciplines should be thoroughly analyzed so as to foster the cultivation of individualization and diversification. aims. For the cultivation of costume art and design talents, an active foreign cooperation model should be adopted. In the teaching, students should be allowed to accept some international fashion elements. At the same time, excellent international talents should be recruited to participate in the domestic clothing innovation training program so as to expand The influence of teaching allows students to better absorb the essence of international excellent culture, and ultimately make the created works 
more diversified artistic value.

The cultivation of talents in the clothing arts is carried out under the background of continuous reform of the industrial chain and rapid changes in the environment of the consumer market. While adjusting the vitality and adaptability of the clothing industry, it should also keep up with the trend of diversification and individualization. The fashion of the teaching environment is indispensable. Only by starting from the rules of art design to train the entire system and keeping up with the pace of the development of the fashion industry, can we educate the comprehensive design talents that satisfy internationalization and diversification.

Although China's fashion design profession has cultivated a lot of talented people and has had more than 40 years of development history, students' creative thinking methods and creativity have not been fully applied in practice. To fully provide students with creative thinking, students must be supported to create and develop innovative brands. Many young designers have emerged in the contemporary era, creating their own brands and opening up sales channels. These are good examples.

Cultivating design-oriented talent is generally divided into two directions. On the one hand, it broadens the field of development of apparel design talents, and on the other hand, it provides technical support for the product designers of product designers. China's clothing brands already have a basically stable market. What we need to do is to give full play to the existing industry models, establish a strong brand concept, and join the international fashion eye, there will inevitably be room for development. It is also necessary to pay attention to the extension of brand activities, with the original brand as the core, and through the exploration of core values to form an industrial chain. By extending the application of various parts of the brand assets, the risk can be reduced to a great extent. Get the most benefit.

\section{Conclusion}

Under the background of the great development of the fashion industry, the garment industry, as an important part of it, is highly malleable. It is the basic consumer industry of the country, and people's material and cultural levels are constantly improving and the times are developing. The garment industry is in the fashion industry. China assumes the responsibility of stimulating the national economy, improving the quality of life of the people, and promoting human civilization. In recent years, the change in the production process of the garment industry, the internal upgrade and the innovation of the channels have all greatly enhanced the overall strength of the company. At the same time, the industry has also enhanced its own original design capabilities in the "Internet+". Under the guidance of the policy, we can more easily understand the development of the industry in the entire field, and provide a good idea on how to cultivate talents suitable for the development of the apparel industry. Of course, there are still many deficiencies in the cultivation of talents in the apparel industry. The education and teaching methods, the actual needs of corporate talents, and how to increase the details of the content and mode of thinking, and promote the construction of resource sharing platforms still need more attention., to overcome more difficulties.

\section{References}

[1] Cao Weicheng, HUANG Yongli. Research on Training Mechanism of Garment Art Design Talents in Fashion Industry Context[J]. Vocational Education News, 2017(29):28-30.

[2] Hou Fengxian. Study on the Training of Fashion Design Talents in Higher Vocational Education under the Interaction of Art and Technology [D]. China Academy of Art, 2016.

[3] Xie Ping, Zhao Ping. Creative Convergence Technology Design and Inheritance Culture: Documentary Construction of the Art Design (Clothing) Specialty of Beijing Institute of Clothing Technology [J]. Beijing Education (Higher Education Version), 2015(01):60-62.

[4] Zhang Na. Reflections and Research on the Follow-up Development of Higher Vocational Art Design Specialty in the Context of University Transformation [D]. Wenzhou University, 2016. 
[5] Teachers and students of the Department of Textiles and Clothing of Lincoln University, Nebraska, USA, visited Donghua University's School of Clothing and Art Design [J]. Shanghai Textile Science and Technology, 2016, 41(07): 67-68. 